\title{
AVALIAÇÃO DO DESMATAMENTO NA ESTAÇÃO ECOLÓGICA RASO DA CATARINA
}

\author{
Betiane Figueredo Vieira $^{1}$; Hermilino Danilo Santana de Carvalho ${ }^{2}$ \\ 1. Bolsista PROBIC/UEFS, Graduanda em Geografia, Universidade Estadual de Feira de Santana, e-mail: \\ betyane_figueredo@hotmail.com \\ 2. Orientador, Departamento de Ciências Humanas e Filosofia, Universidade Estadual de Feira de Santana, e-mail: \\ hdscarvalho@gmail.com
}

PALAVRAS-CHAVE: Desmatamento; Unidade de conservação; Sensoriamento remoto

\section{INTRODUÇÃO}

De acordo com o IBAMA (2010) o desmatamento é a operação de supressão da vegetação nativa de determinada área para o uso do solo. $\mathrm{O}$ desmatamento é uma das práticas mais degradadoras ao meio ambiente, pois a ausência de cobertura vegetal expõe os solos à erosão, causando alterações no ecossistema. Tendo em vista a presença de comunidades próximas a Estação Ecológica Raso da Catarina, o que põe em risco sua preservação, buscou-se avaliar o desmatamento nessa unidade de conservação, com a finalidade de verificar a real situação da cobertura vegetal, haja vista, a ocorrência de processos de degradação ambiental/desmatamento na região nordeste da Bahia, onde está localizada essa Estação Ecológica.

\section{MATERIAL E MÉTODOS OU METODOLOGIA (ou equivalente)}

Foram realizados os seguintes procedimentos de pesquisa: primeiro foi realizada uma revisão bibliográfica sobre a temática, em seguida, selecionou e levantou as imagens de satélites no site do INPE, organizou um banco de dados com essas imagens, fez-se a aplicação do NDVI, com consequente elaboração dos mapas. Após essa etapa, foi feito o levantamento de dados de precipitação no site do INMET e elaboração de gráficos com esses dados. Na etapa final, interpretou e analisou os resultados.

\section{RESULTADOS E/OU DISCUSSÃO (ou Análise e discussão dos resultados)}

As figuras a seguir mostram os mapas das imagens processadas referente aos cálculos de NDVI, para os dois períodos estudados, um úmido e outro seco, de cada ano (1984, 1994, 2004 e 2009). As cores esverdeadas quer dizer alto vigor vegetativo e as alaranjadas e avermelhadas vegetação estressada, ou sem vegetação.

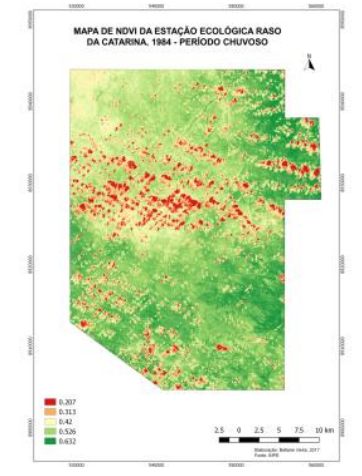

Figura 1:Período chuvoso $(08 / 06 / 1984)$.

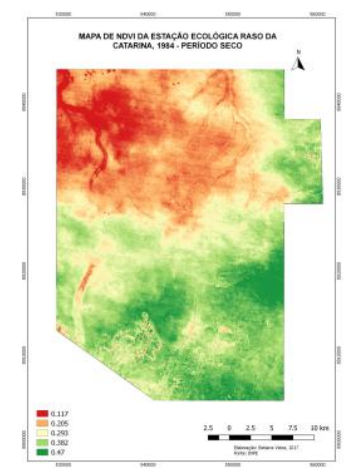

Figura 2: Período seco $(28 / 09 / 1984)$

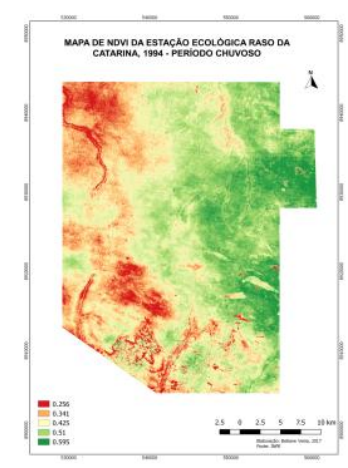

Figura 3: Período chuvoso (19/05/1994)

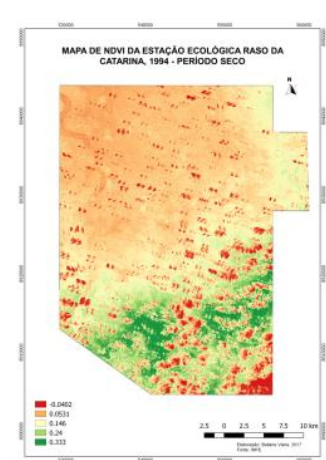

Figura 4: Período seco (11/11/1994) 
Os mapas de NDVI demonstram que nos períodos chuvosos a Esec apresentou maior vigor vegetativo que nos períodos secos. A escassez de chuvas nos períodos secos leva a ausência de água no solo da caatinga influenciando diretamente no crescimento e desenvolvimento da vegetação - a perda de umidade resulta em uma vegetação estressada, menos densa e ocasiona perda de biomassa vegetal. Verificam-se grandes manchas avermelhadas na porção norte da unidade nos períodos secos de 1984 e 1994, indicando que a vegetação estava estressada ou rala.

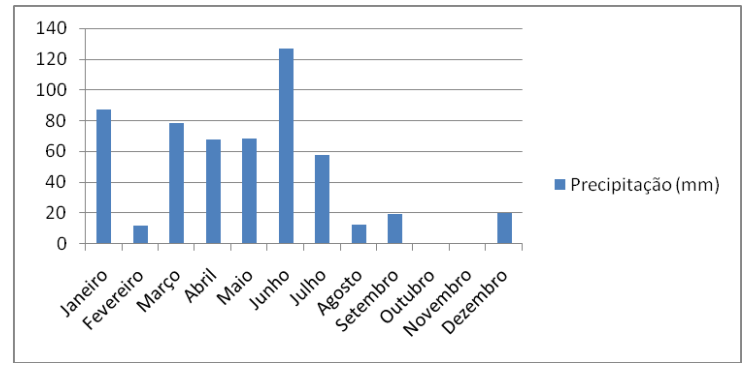

Gráfico 1: Precipitação mensal da Esec Raso da Catarina (1994) Elaboração: Betiane Vieira, 2017; Fonte: INMET, 2017.

O gráfico de precipitação mostra como foi o regime pluviométrico do ano de 1994. Observa-se que no período de agosto a dezembro a Esec apresentou baixos índices pluviométricos, e que no período de janeiro a julho as chuvas foram constantes e em quantidades significativas. Isso influenciou diretamente na vegetação.

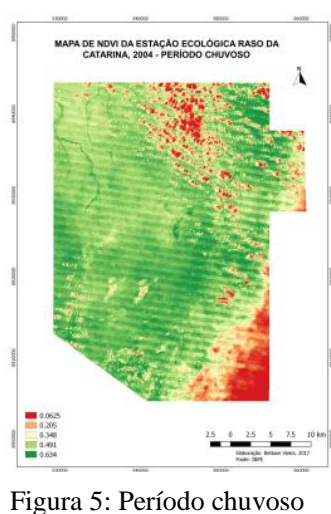
$(24 / 02 / 2004)$

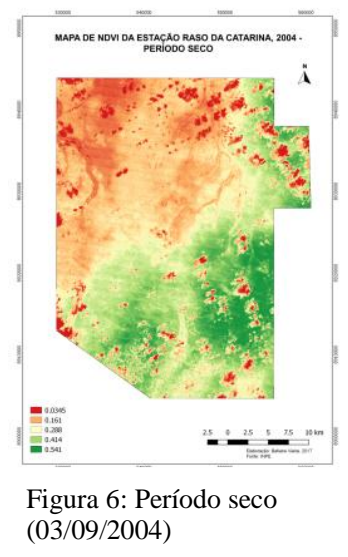

Figura 6: Período seco
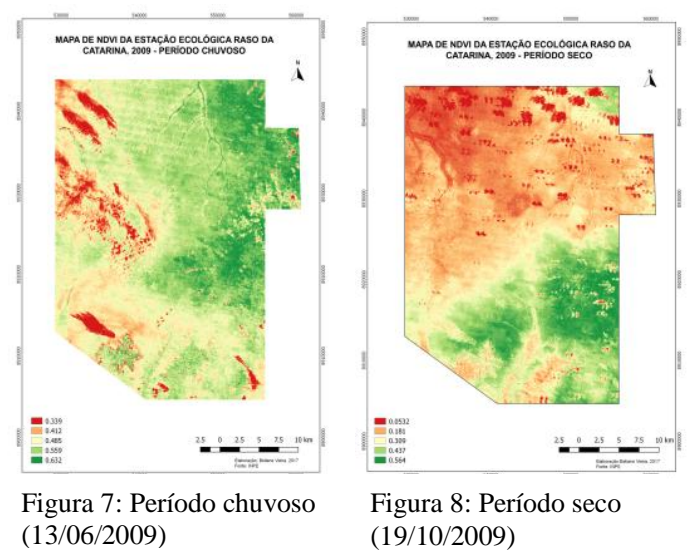

Observa-se nos mapas que nos períodos secos de 2004 e 2009 a Esec apresentou baixos valores de NDVI, principalmente, na parte norte da unidade. Nos períodos chuvosos a Esec apresentou médios valores de NDVI. As manchas vermelhas são decorrentes das interferências de nuvens, e, portanto esses valores são desconsiderados nessa análise. No período chuvoso de 2009 a UC registrou baixo NDVI na parte oeste da área. 


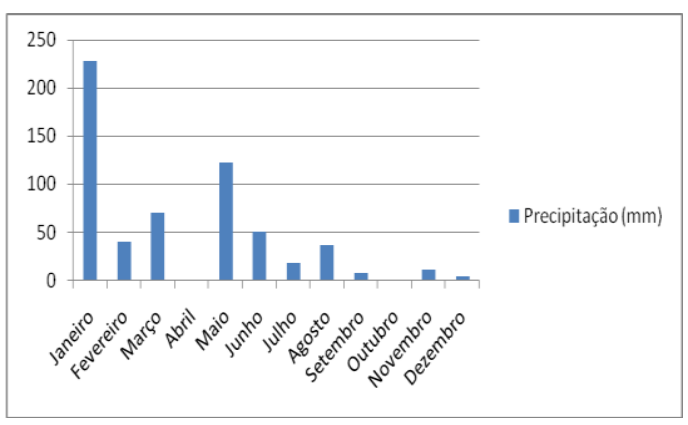

Gráfico 2: Precipitação mensal da Esec Raso da Catarina (2004)

Elaboração: Betiane Vieira, 2017; Fonte: INMET (2017)

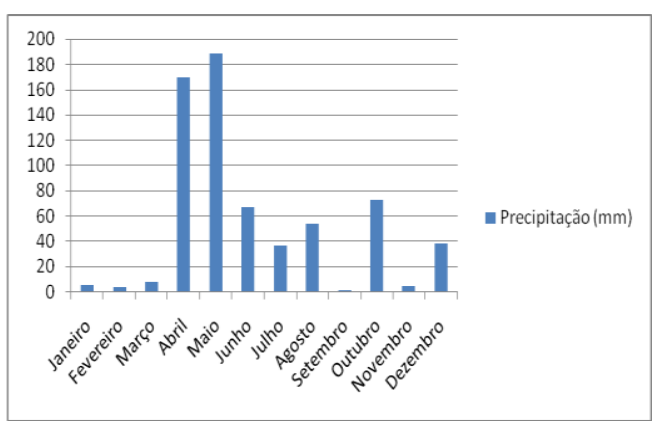

Gráfico 3: Precipitação mensal da Esec Raso da Catarina (2009)

Elaboração: Betiane Vieira, 2017; Fonte: INMET (2017)

Os gráficos de precipitação dos anos de 2004 e 2009 mostram a dinâmica das chuvas na Esec e reafirma a sua influência na vegetação. Em 2004 de setembro a dezembro as chuvas foram poucas e em pequeno volume, já de janeiro a junho a quantidade de chuvas foi maior. Em 2009, o maior volume de chuvas foi de abril a agosto, e de setembro a dezembro as chuvas foram mais escassas.

Pôde-se observar através dos mapas que a Esec durante o período analisado (1984 a 2009) apresentou baixos á médios índices de NDVI. O valor máximo de NDVI atingido foi 0,63. As variações desse índice se deram conforme o período do ano - seco ou chuvoso. Isso demonstrou a dinâmica da cobertura vegetal da Esec ao longo dos anos estudados.

A Esec Raso da Catarina apresentou valores de NDVI mais expressivos nos períodos chuvosos do que nos períodos secos. O menor valor de NDVI registrado nessa UC durante o período analisado (1984-2009) foi de 0,05. Essa baixa densidade vegetal nessa área pode ser o reflexo de pouca biomassa vegetal ou solo desnudo. O que reafirma a influência da sazonalidade climática na vegetação, através da ocorrência ou não de precipitações.

Foi observada a repetição de grandes manchas alaranjadas ao norte da área da Esec durante o período (1984-2009). Essas manchas alaranjadas corresponderam aos menores valores de NDVI, valores esses muito próximos a zero. Isso demonstra que nessa porção da Estação a biomassa vegetal apresentou menor densidade em diferentes momentos, ou melhor, em anos diferentes.

De acordo com o relatório elaborado em 2015 pela equipe de pesquisa da Universidade Federal de Campina Grande (UFCG), vem ocorrendo conflitos socioambientais dentro dos limites da Esec por conta de práticas como caças predatórias e pastagem extensiva de gado, conhecida como "fundo de pasto" - um modo tradicional da pecuária, em que há uma articulação de terrenos familiares e áreas de uso comum, onde se criam caprinos e ovinos à solta e em pastagem nativa (FREIRE et al., 2015).

A equipe de pesquisa da UFCG destacou no relatório que o gestor da Esec Raso da Catarina, Sr. José Tiago Almeida dos Santos, salientou que "os principais impactos se referem à falta de uma demarcação dos limites e fechamento da área ('cercamento')" (FREIRE et al, 2015, p.11). Essa falta de demarcação leva então a ocorrência de impactos sob os recursos ambientais da UC.

Ainda de acordo com o gestor da unidade, nesses casos, embora a fiscalização do ICMBio tenha os instrumentos legais para apreensão dos animais, esta não é feita para não causar conflitos socioambientais significativos com as populações tradicionais e de alta vulnerabilidade social que vivem no entorno da estação (FREIRE et al, 2015). 
Pôde-se perceber através dos mapas de NDVI que a vegetação no período seco se apresentava sempre estressada, porém quando chegava o período de chuvas se regenerava, se revitalizando e mostrando vigorosidade, por conta da umidade. Isso demonstra a relação do padrão sazonal da vegetação com a precipitação. Dessa maneira entende-se que o regime pluviométrico foi um dos fatores da dinâmica da cobertura vegetal da Esec no período de 1984 a 2009. Além desse fator, a ocorrência de práticas predatórias, como a pecuária extensiva (fundo de pasto) e a caça ilegal nos limites da unidade podem ter interferido nas mudanças da cobertura vegetal nesse período, intensificado o desgaste da vegetação nos períodos secos. A baixa densidade de biomassa vegetal na porção norte da Esec, registrada em diferentes anos, pode ser decorrente do baixo índice pluviométrico nessa área, como também dessas atividades predatórias realizadas pelas comunidades locais. Essas práticas podem está levando a supressão da vegetação nativa, causando mudanças na paisagem, caracterizando-se assim desmatamento na UC.

\section{REFERÊNCIAS}

COSTA JÚNIOR, W. R.; LIMA, S. P. M.; CAMPOS, G. S.; SILVA, K. A. F. Análise do desmatamento em áreas protegidas: $O$ caso da RDS Uatumã. REVISTA GEONORTE, V. 1, N.4, p. 125-137, 2012.

FREIRE, N. C. F.; MOURA, D. C.; SILVA, J. B. Estação Ecológica Raso da Catarina: a preservação da biodiversidade na caatinga. Cap. 6, Relatório parcial da pesquisa Mapeamento e Análise Espectro-Temporal das unidades de conservação de Proteção Integral da Administração Federal no Bioma Caatinga. Recife, UFCG, 2015.

INSTITUTO BRASILEIRO DO MEIO AMBIENTE E DOS RECURSOS NATURAIS RENOVÁVEIS (IBAMA) -Ministério do Meio Ambiente. Brasília-DF, Brasil, 2010. Disponível em: http://www.ibama.gov.br/areas-tematicas/desmatamento, Acesso em: 21 de mar. 2016

INSTITUTO CHICO MENDES DE CONSERVAÇÃO DA BIODIVERSIDADE(ICMBio) - Ministério do Meio Ambiente. Brasília-DF, Brasil, 2002.Disponível em: $<$ http://www.icmbio.gov.br/portal/biodiversidade/unidades-deconservacao/biomas-brasileiros.html>Acesso em: 20 de mar. 2016.

MELO, E. T.; SALES, M. C. L.; OLIVEIRA, J. G. B.; Aplicação do Índice de Vegetação por Diferença Normalizada (NDVI) para análise da degradação ambiental da microbacia hidrográfica do Riacho dos Cavalos, Crateús-CE. Curitiba, UFPR, RA'EGA, 2011.

NOVO, E. L. M. Sensoriamento remoto: princípios e aplicações. Edgar Blucher, São Paulo, 1989.

PAIXÃO, R. M. C. Avifauna da Estação Ecológica do Raso da Catarina, Bahia, Brasil. João Pessoa, UEPB, 2012.

VALE, Raquel M. C., et al Degradação ambiental e processos de desertificação no Estado da Bahia: relatório técnico para convênio Universidade Estadual de Feira de Santana / Raquel de Matos C. do Vale...[et al.]. Salvador: INGÁ, 2010.

VALLEJO, L. R. Unidade de Conservação: uma discussão teórica à luz dos conceitos de território de políticas públicas.GEOgraphia, v.4, n. 8, p. 57-78, jul./dez. 2002. Disponível em: Acesso em: 12 Dez. 2016. 